\title{
Study on Teaching Efficiency and Teaching Faith of Career Development Education for Junior High School Teachers
}

\author{
Chang-Fu Lin, Tsai-Ku Liao, Chin-Wen Liao, and Chia-Ling Shih
}

\begin{abstract}
The objective of this research is to study the difference and correlation of teaching faith and teaching efficiency of career development education for junior high school teachers with different background variables. The theory basis of this research comes from studying, re-arranging, and analysis of the literatures. According to the objectives of this research, the results are concluded as below:

1). The junior high school teachers have firm teaching faith of career development.

2). The junior high school teachers have good teaching efficiency of career development.

3). The junior high school teachers attended relevant research of career development education, have the firmest overall teaching faith of career development.

4). The fresh teachers, experienced teachers and teachers with master or above educational background have the best overall teaching efficiency of career development.

5). The junior high school teachers with higher teaching faith of career development, they will have higher teaching efficiency of career development.
\end{abstract}

Index Terms-Teaching efficiency, teaching faith, career development education.

\section{INTRODUCTION}

\section{A. Background and Motivation}

Taiwan introduces the 12-year Basic Education. The implementation of adaptive counselling will affect whether the graduated junior high school students choosing the suitable schools according to the own aptitude, interest and ability. It will even affect the career path and career plan. The way for the teachers facing the change of educational environment, understanding the importance of career development to students, re-establishing the own teaching faith firmly and keeping up the teaching enthusiasm and ideal are the initial motivation of this research [1].

How is the teaching efficiency of career development of the junior high school teachers nowadays? How is the teaching efficiency of the junior high school teachers for counselling students about self-awareness and career planning? This is the second motivation of the research.

Manuscript received April 20, 2015; revised June 24, 2015.

The authors are with the Department of Industrial Education and Technology, National Changhua University of Education, Changhua, Taiwan (e-mail: terence650607@hotmail.com, tsaikuliao@gmail.com, malisa168@yahoo.com.tw, tcwliao@cc.ncue.edu.tw).
Does the teaching faith of the teachers affect the teaching efficiency? What is the effect to the teaching efficiency of the teachers? What is the correlation between teaching faith and teaching efficiency? This is the third motivation of the research.

\section{B. Objective}

According to the motivation mentioned above, this research has studied the correlation between "teaching faith" and "teaching efficiency" of the career development education for junior high school teachers. The major objectives include:

1) Understand the current circumstance of teaching faith and teaching efficiency of career development education for junior high school teachers.

2) Compare the teaching faith and teaching efficiency of career development education for different background variables of junior high school teachers.

3) Compare the teaching efficiency of career development education for different background variables of junior high school teachers.

4) Study the correlation between teaching faith and teaching efficiency of career development education for junior high school teachers.

\section{RESEARCH DESIGN AND IMPLEMENTATION}

The objective of this research is to study the existing circumstance of teaching faith and teaching efficiency of career development education for junior high school teachers, and the correlation of these two items. Besides, the difference of teaching faith and teaching efficiency of the career development education for different background of teachers, and the correlation of teaching faith and teaching efficiency of career development education for the teachers are studied.

\section{A. Research Structure}

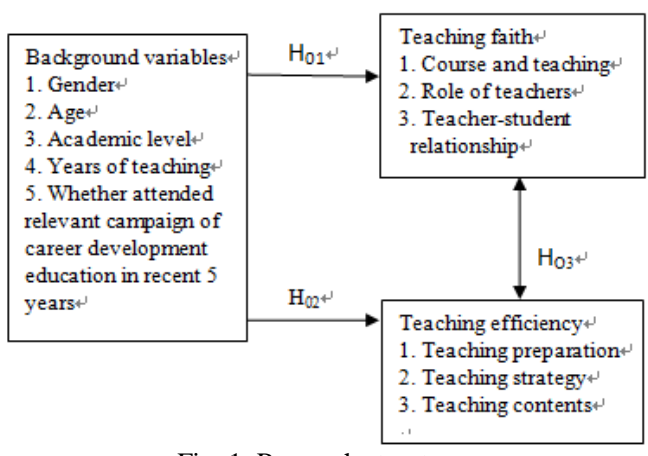

Fig. 1. Research structure. 
The objective of this research is to study the correlation of teaching faith and teaching efficiency of career development education for the junior high school teachers. According to motivation, objective, and the result of studying literature, the structure of this research is designed and is shown in Fig. 1.

\section{B. Object of Study}

The objective of this research is to study the correlation of teaching faith and teaching efficiency of career development education for the junior high school teachers. The public junior high school teachers in 2013 were the object of study.

\section{1) Object of pre-test questionnaire}

Regarding the number of participants for the pre-test, For the number of participants selected for the pre-test, 3 to 5 times of number of question of "scale" in pre-test should be chosen [2]. There are 27 questions for this "Scale of teaching efficiency of career development education for teachers" pre-test. Therefore, 192 participants were selected as the number of pre-test samples.

The researcher delivered the pre-test questionnaires on March 2014. Totally 192 questionnaires were delivered and 186 questionnaires returned. There were 173 valid questionnaires and 13 invalid questionnaires. The effective response rate was $90.1 \%$.

\section{2) Object of official questionnaire}

The public junior high school teachers of a region in 2014 were the population of sampling of this research. According to the scale of the schools, stratified random sampling was applied. The ratio of selected samples depended on the scale of the schools. Totally, 696 teaches were selected as the object of the questionnaire survey. Researchers delivered the official questionnaires on May 2014. Totally 696 questionnaires were delivered and 665 questionnaires returned. There were 644 valid questionnaires and 21 invalid questionnaires. The effective response rate was 96.8\% [3].

\section{Research Tool}

The questionnaire survey was applied for this research. It was based on the objectives of the research and the analysis of relevant literatures. Besides, the difference of teaching faith and teaching efficiency of career development education for different background variables of junior high school teachers would be studied.

The contents of the questionnaire are described below:

\section{1) Pre-test questionnaire compiling}

\section{a) Basic information compiling}

Background information of the teacher includes gender, age, academic level, years of teaching, whether attended relevant campaign in recent 5 years.

\section{b) Teaching faith scale of career development education for teachers}

The course and teaching of career development education, role of teachers and teacher-student relationship are included

\section{c) Teaching efficiency scale of career development education for teachers}

The teaching preparation of career development education, teaching strategy and teaching contents are included.

2) Filling up the scale and score counting

The Likert Scale has been applied to this scale. According to the view of the participates, they may select "Totally agree", "Agree", "No opinion", "Disagree" and "totally disagree" for each question, and 5 to 1 scores will be counted respectively. The higher scores represent the teacher has firmer teaching faith and higher teaching efficiency of career development education.

\section{3) Expert content validity}

After the scale of this research was compiled according to the relevant literatures, experts were invited to review and examine the contents and relevance of the scale. The revising opinion was also proposed.

\section{4) Official questionnaire}

The official questionnaire was divided into 3 parts. The first part was about the basic information of the participant. The second part was "Teaching faith scale of career development education for teachers" . The third part was "Teaching efficiency scale of career development education for teachers" [4].

\section{Research Implementation}

Sudman pointed out that for regional research [2], the average samples of 500-1000 people would be appropriate. For national research, the average samples of 1,500-2,500 people would be appropriate [5]. The population of this research was 5,456 people and the sampling would be 696 people.

\section{DATA ANALYSIS AND DISCUSSION}

The questionnaire survey of this research included background variables of junior high school teachers, teaching faith scale of career development education and teaching efficiency scale of career development education. These were to verify the hypothesis of this research.

\section{A. Background Variables of Junior High School Teachers}

\section{1) Gender}

There were 201 male teachers, which occupied $31.2 \%$ of valid samples. There were 443 female teachers, which occupied $68.8 \%$ of valid samples. Most of the samples in this research were female teachers.

\section{2) Age}

There were 101 teachers with 30 years old or above, which occupied $15.7 \%$ of the valid samples. There were 284 teachers with 31-44 years old, which occupied $44.7 \%$ of the valid samples. There were 212 teachers with 41-50 years old, which occupied $32.9 \%$ of the valid samples. There were 47 teachers with 51 years old or above, which occupied $7.3 \%$ of the valid samples. Most of the samples in this research were junior high school teachers with 31-40 years old.

\section{3) Academic level}

There were 189 teachers graduated from general universities, for which they occupied $29.3 \%$ of the valid samples. There were 163 teachers graduated from normal universities, for which they occupied $25.3 \%$ of the valid samples. There were 292 teachers with master degree or above, for which they occupied $45.3 \%$ of the valid samples. Most of the samples of this research had master degree or above. 


\section{4) Years of teaching}

There were 108 junior high school teachers with years of teaching 5 years or below, for which they occupied $16.8 \%$ of valid samples. There were 195 junior high school teachers with years of teaching 6-10 years, for which they occupied $30.3 \%$ of valid samples. There were 125 junior high school teachers with years of teaching 11-15 years, for which they occupied $19.4 \%$ of valid samples. There were 103 junior high school teachers with years of teaching 16-20 years, for which they occupied $16.0 \%$ of valid samples. There were 113 junior high school teachers with years of teaching 21 years or above, for which they occupied $17.5 \%$ of valid samples. The junior high school teachers with years of teaching 6-10 years had the highest ratio, while those with years of teaching 11-15 had the second highest.

\section{5) Whether attended relevant campaign of career development education in recent 5 years}

468 teachers had attended relevant campaign of career education in recent 5 years, for which they occupied $72.7 \%$ of valid samples. 176 teachers had not attended relevant campaign of career education in recent 5 years, for which they occupied $27.3 \%$ of valid samples. Over $70 \%$ of teachers had attended relevant campaign of career education in recent 5 years,

\section{B. Analysis on Teaching Faith and Teaching Efficiency of Career Development Education for Junior High School Teachers}

1) In the teaching faith scale of career development education for junior high school teachers, the average scores of the 3 aspects, including "course and teaching", "role of teachers" and "teacher-student relationship", are between 3.83 and 4.10. This represents that the junior high school teachers trend to "agree" on all aspects of teaching faith of career development education. The overall average scores are 4.03. This shows that the junior high school teachers trend to "agree" on overall teaching faith of career development education.

2) In the teaching efficiency scale of career development education for junior high school teachers, the average scores of the 3 aspects, including "teaching preparation", "teaching strategy", and "teaching contents", are between 3.70 and 3.97. This represents that the junior high school teachers trend to "agree" on their own teaching efficiency of career development education. The overall average scores are 3.85. This represents that the junior high school teachers trend to "agree" on their own teaching efficiency of career development education.

\section{Analysis on Difference of Teaching Faith Of Career Development Education for Background Variables of Junior High School Teachers (Hypothesis Test)}

1) For the "course and teaching" $(t=.35, p>.05)$, "role of teachers" $\quad(t=.07, \quad p>.05)$ and "teacher-student relationship" $(t=-.54, p>.05)$ of career development education, different gender of junior high school teachers have not reached significant difference for any aspect of the teaching faith. The overall teaching faith has not reached significant difference $(t=-.14, p>.05)$. This represents that different gender of junior high school teachers have no significant difference on teaching faith of career development education.

2) For the "course and teaching" $(F=3.08, p<.05)$, "role of teachers" $(F=4.44, \quad p<.01)$ and "teacher-student relationship" ( $F=9.26, p<.001)$ of the teaching faith, the junior high school teachers with different ages have reached significant difference of these 3 aspects. They have also reached significant difference on overall difference $(F=7.42, p=<.001)$. This represents that different ages of junior high school teachers have significant difference on teaching faith of career development education.

3) Analysis on teaching faith of career development education for junior high school teachers with different academic level

The teaching faith of all aspects, including "course and teaching" $(F=2.28, p>.05)$, "role of teachers" $(F=2.12, p>.05)$ and "teacher-student relationship" $(F=1.27, p>.05)$, and the overall teaching faith have not reached the significant difference. This represents that the different academic level of the junior high school teachers do not have difference on teaching faith of career development education

1) Analysis on teaching faith of career development education for junior high school teachers with different years of teaching

The "course and teaching" $(F=2.04, p>.05)$ and "role of teachers" $(F=2.01, p>.05)$ of teaching faith have not reached significant difference. The "teacher-student relationship" of teaching faith has reached significant difference $(F=4.45$, $p<.01)$. The overall teaching faith have also reached significant difference $(F=3.80, p<.05)$. This represents that the junior high school teachers with different years of teaching, have difference on teaching faith of career development education

2) Analysis on teaching faith of career development education for junior high school teachers attended or not attended relevant campaign in recent 5 years

The 3 aspects of teaching faith, including "course and teaching" $(t=3.77, p<.001)$, "role of teachers" $(t=2.47, p<.05)$ and "teacher-student relationship" $(t=2.20, p<.05)$, have reached the significant difference. The overall teaching faith has also reached significant difference $(t=3.30, p<.01)$. This represents that the junior high school teachers attended the campaign or not have difference on teaching faith of career development education.

\section{Analysis on Difference of Teaching Efficiency of Career Development Education for Background Variables} of Junior High School Teachers (Hypothesis Test)

1) For the "teaching preparation" $(t=1.88, p>.05)$, "teaching strategy" $(t=.14, p>.05)$ and "teaching contents" $(t=.69$, $p>.05)$ of career development education, different gender of junior high school teachers have not reached significant difference for any aspect of the teaching efficiency. The overall teaching efficiency has not reached significant difference $(t=.93, p>.05)$. This represents that different gender of junior high school teachers have no significant difference on teaching efficiency of career development education.

$2)$ For the "teaching preparation" $(F=8.41, \quad p<.001)$, "teaching strategy" $(F=7.40, p<.001)$ and "teaching contents" $(F=6.76, p<.001)$ of the teaching efficiency, 
the junior high school teachers with different ages have reached significant difference of these 3 aspects. The overall teaching efficiency has also reached significant difference $(F=8.24, p<.001)$. This represents that different ages of junior high school teachers have significant difference on teaching efficiency of career development education.

3) The "teaching contents" of career development education for junior high school teachers with different academic level has not reached significant difference $(F=1.72$, $p>.05)$. However, the other 2 aspects, including "teaching preparation" $(F=6.06, p<.01)$ and "teaching strategy" $(F=3.57, p<.05)$ have reached significant difference. The overall teaching efficiency has also reached significant difference $(F=4.12, p<.05)$. This represents that the different academic level of the junior high school teachers have difference on teaching efficiency of career development education.

4) The different aspects, including the "teaching preparation" $(F=4.29, \quad p<.01)$, "teaching strategy" $(F=4.33, \quad p<.01)$ and "teaching contents" $(F=5.35$, $p<.001)$ of teaching efficiency of career development education for junior high school teachers with different years of teaching have reached significant difference. The overall teaching efficiency has also reached significant difference $(F=5.02, p<.01)$. This represents that the junior high school teachers with different years of teaching, have difference on teaching efficiency of career development education.

5) The 3 aspects of teaching efficiency, including "teaching preparation" ( $t=1.09, p>.05)$, "teaching strategy" $(t=1.03$, $p>.05)$ and "teaching contents" ( $t=1.75, p>.05)$, have not reached the significant difference. The overall teaching efficiency has not reached significant difference neither $(t=1.38, p>.05)$. This represents that the junior high school teachers attended the campaign or not have no difference on teaching efficiency of career development education.

\section{CONCLUSION AND SUGGESTION}

\section{A. Conclusion}

1) Junior high school teachers have firm teaching faith of career development education.

2) Junior high school teachers have good teaching efficiency of career development education.

3) The junior high school teachers who have the longest years of teaching and attended relevant campaign of career development education in recent 5 years, have the firmest overall teaching faith of career development education.

4) The youngest and inexperienced teachers, the oldest and experienced teachers, and the junior high school teachers with master degree or above, have the best overall teaching efficiency of career development education.

5) The teaching faith and teaching efficiency of career development education of junior high school teachers have high positive correlation. The one with firmer teaching faith, the teaching efficiency will be better.

\section{B. Suggestion}

According to the data analysis of questionnaire survey of this research, the following suggestions are proposed to education authority, schools, and teachers:

\section{1) Suggestion to education authority}

1) Promote the junior high school teachers to participate in career experience sharing and career plan campaign in order to increase the teaching efficiency of student counselling.

2) Establish career development education resource center

\section{2) Suggestion to school administration}

1) Open the teacher professional growing community and implement the integration of career development to all subjects.

2) Implement administration to support teaching, respect the autonomy of teaching profession and care for teachers.

3) Implement division of labor with individual responsibility to school administration. Establish perfect system to assist handling relevant activities of career development education.

4) Assist empowering the teachers and increase the achievement of counseling for fitness.

\section{3) Suggestion to teachers}

1) Think positive. Accept new concept and challenge.

2) Attend the relevant research and study of career development.

3) Self-affirmation, guide the compatibility and suitability of the students

4) Build up the good teacher-student relationship.

\section{REFERENCES}

[1] K. Jsakyte and M. Le, "Organizational commitment of social workers: An exploratory study," Administration in Social Work, vol. 33, no. 3, pp. 227-241, Jan. 2009.

[2] E. R. Babbie, The Practice of Social Research, Belmont, CA: Wadsworth, ch. 3, 2004

[3] M.-L. Wu and J.-T. Chu, SPSS and Statistical Analysis, Taipei: Wunan, ch. 3, 2013.

[4] K. D. Bailey, Methods of Social Research, New York: The Free Press, ch. 4, 1987.

[5] J. H. McMillan and S. Schumacher, Research in Education: Evidence Based Inquiry, Boston: Allyn \& Bacon, ch. 2. 2006.

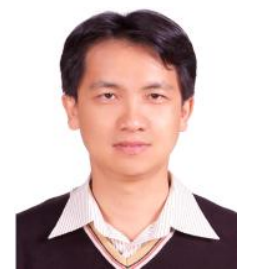

Chang-Fu Lin received the M.S. degree at the Department of Graduate Institute of Primary and Secondary Education from National Chiayi University in 2003, and currently he is a doctoral student at the Department of Industrial Education from National Changhua University, Taiwan, R.O.C. Since August 2012, he has been a director of General Affairs Office in Tonan Senior High School in Taiwan, R.O.C. Since August 2000, he has taught courses in everyday science technology in the same school.

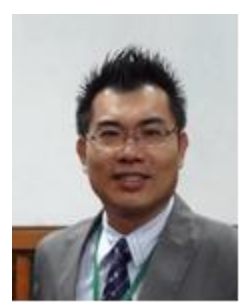

Tsai-Ku Liao received the M.S. degree at the Department of Geography from National Taiwan Normal University in 2006, and currently he is a Ph.D candidate at the Department of Industrial Education from National Changhua University, Taiwan, R.O.C Since August 2008, he has been a director of Student Affairs and Library in National Taichung First Senior High School (TCFSH) in Taiwan, R.O.C. Since August 1998, he has taught courses in Geogrpahy, GIS, Monographic study in the same school. 


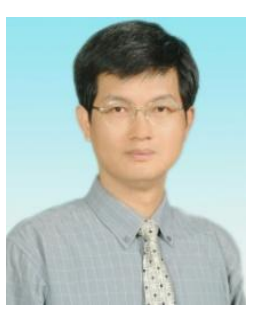

Chin-Wen Liao received both the M.S. and Ph.D. degree in industrial education from National Taiwan Normal University, Taiwan, R.O.C. in 1994 and 2002, respectively. Since August 2011, he has been a professor in the Department of Industrial Education and Technology at National Changhua University of Education (NCUE) in Taiwan, R.O.C. At the same time. He teaches courses in technology and vocational education, energy education, teacher education, course and teaching, organization learning. His research interests include technology and vocational education, energy education of technology, automatic control, and knowledge management.

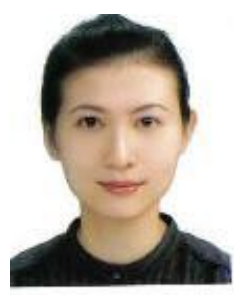

Chia-Ling Shih is a doctoral student of the Department of Industrial Education and Technology, National Changhua University of Education (NCUE), Taiwan and now a high school teacher in Taiwan. 